\title{
Saber Histórico de Professores nas Séries Iniciais: algumas perspectivas de ensino em sala de aula
}

Marlene CAINELLI ${ }^{I}$

Tiago Costa SANCHES

\section{RESUMO}

Este artigo tem como objetivo discutir os primeiros resultados da pesquisa realizada no mestrado em educação pela Universidade Estadual de Londrina. A pesquisa consiste em tentar perceber como os professores das series iniciais mobilizam os saberes teóricos e metodológicos específicos da disciplina de história e como estes se apresentam na prática escolar destes professores. A pesquisa estásendo realizada com professores de primeira a quartasérie de uma escola municipal, radicada no município de Cambé. 0 modelo de pesquisa será qualitativo de investigação, pois este "[...] enfatiza mais o processo do que o produto e se preocupa em retratar a perspectiva dos participantes" (ANDRÉ, 1986, p.13).

A pesquisa se encontra em estágio de cruzamento de dados levantados e conclusão, neste artigo iremos discutir os resultados colhidos no teste piloto realizado em uma escola particular do município de Londrina com professores das séries iniciais.

Palavras-chaves: Ensino de história, Saber Histórico, Séries iniciais,educação histórica

0 Ensino de História vive hoje um momento de definição conceitual provocado pelo processo de amadurecimento que vem sendo consolidado por pesquisas e investigações realizadas em programas de pós-graduação por pesquisadores em instituições brasileiras e internacionais. Neste sentido muitos conceitos e categorias de análise estão sendo definidos e alguns revistos, conceitos como Didática da História, Educação Histórica, Saber Histórico, Saber Histórico

\footnotetext{
1 Doutora em História. Universidade Estadual de Londrina

2 Mestrando em Educação pela Universidade Estadual de Londrina, Paraná.
} 
Escolar, Transposição Didática.

Entre as questões que oportunizam discussões sobre 0 repertório de conhecimentos que envolvem as pesquisas em ensino de história e didática da história podemos afirmar que se destaca a linha de investigação em Educação histórica. Segundo Lee (2003) a educação histórica sustenta-se no desenvolvimento da relação que os sujeitos estabelecem com as idéias constitutivas da própria natureza da História, como as fontes, narrativas e explicações históricas, dizendo respeito aos próprios conteúdos e conceitos históricos, entre eles imigração, religião, trabalho, entre outros.

Ainda podemos afirmar que a pesquisa em educação histórica trouxe, para este campo de investigação, discussões e conceitos ainda pouco trabalhados em nossa área até o momento - conceitos como evidência histórica, cognição situada, empatia histórica. Aliado à questão da pesquisa empírica, o entendimento do significado dos mesmos foi o primeiro grande desafio dos pesquisadores que se aventuraram pela investigação nessa linha de investigação.

$\mathrm{Na}$ pesquisa ${ }^{3}$ em questão trabalhamos na área de investigação em educação histórica tendo a sala de aula e a pesquisa empírica como fonte de informação. Neste artigo iremos trabalhar com 0 teste piloto que foi aplicado com o intuito de consolidar os instrumentos de pesquisa. Seus dados são instigantes e mereceu de nossa parte uma análise significativa e aqui apresentamos seus resultados.

Os professores pesquisados são profissionais formados pelo curso de pedagogia, ou seja, não tiveram a formação especifica em licenciaturas específicas ministrando aulas de várias disciplinas entre elas a disciplina de História nas séries iniciais. Estes professores tiveram em sua formação uma disciplina que aborda apenas a metodologia de ensino das licenciaturas específicas no caso de História, em algumas universidades ainda se ministra esta disciplina conjuntamente com a pedagogia. Neste sentido a pesquisa tenta mapear quais os conhecimentos sobre a história estes professores adquirem e como mobilizam estes conhecimentos em sala de aula. Para tanto pesquisamos alguns conceitos formulados por estes professores com referencia ao saber histórico.

Nesta pesquisa denominamos de saber Histórico a capacidade que 0

\footnotetext{
3 Pesquisa de mestrado do aluno Tiago Costa Sanches orientado pela professora Doutora Marlene Cainelli no mestrado em educação da Universidade Estadual de Londrina
} 
professor adquire em dominar aspectos relativos ao campo da teoria da História, ou seja, um saber específico, validado, organizado e comunicável. Consiste em ter ciência sobre como o conhecimento histórico é produzido. É ter conhecimento do funcionamento da matriz disciplinar da história. Este conceito segundo Rusen (2001:29) significa "o conjunto sistemático dos fatores ou princípios do pensamento histórico determinantes da ciência da história como disciplina especializada".

Neste sentido entendemos que 0 professor ao realizar inferências sobre 0 passado faz uso deste saber e deveria estar consciente que aquele passado pesquisado não trará a verdade absoluta sobre o fato, que o Conhecimento Histórico, produto de diversas pesquisas historiográficas, não é único e definitivo, foi produzido pelo homem e está passivo de subjetividade por mais objetivo que tente ser.

Para realizar comparações entre o passado e o presente através de categorias históricas como progresso, permanências, continuidades, mudanças o professor ou pesquisador deveria dominar algumas categorias do "saber histórico" entre elas a questão da temporalidade bistórica. 0 mesmo ocorre com o uso dos conceitos históricos, pois este "É o material com que são construídas as teorias históricas e constitui 0 instrumento lingüístico mais importante do historiador." RUSEN (2007). Entendemos que ao lidar com os conhecimentos históricos e com as categorias que formam este conhecimento o professor das séries iniciais estaria de certa forma trabalhando com 0 saber histórico.

Ao assistir uma aula de História ministrada por um professor das séries iniciais geralmente pedagogo, objetivamos analisar se a disciplina de Metodologia de Ensino de História, realizada nos cursos de formação inicial, é capaz de formar estes saberes específicos da área da História. Para tal as analises foram pautadas em três categorias que arriscamos afirmar compõe o Saber Histórico, o conceito e uso da verdade histórica, a formação de conceitos históricos e por fim o domínio da temporalidade históricá.

A pesquisa empírica: questionários como instrumentos de investigação A diferenciação entre saber, conhecimento e informação é de extrema

\footnotetext{
${ }^{4} \mathrm{Na}$ dissertação iremos verificar estes elementos durante as aulas dos professores, em sua fala, exercícios e atividades. Em seguida aplicaremos outro instrumento sob forma de questionário, indagando sobre os mesmos elementos analisados durante a observação. 0 último passo será confrontar os resultados, obtidos nos questionários, com os elementos de sua prática docente.
} 
importância para a pesquisa, pois acreditamos que estes elementos irão se mesclar durante as observações da prática do professor. Por exemplo: o professor pode utilizar informações históricas contidas nos livros didáticos ou textos da internet transmitindo aos alunos sem qualquer contextualização, intervenção ou reflexão. Pode ainda inserir em sua fala conhecimentos particulares de sua vivência ou histórias de sua família sem qualquer validade histórica. Não estamos afirmando aqui que estes elementos não possam ser utilizados em sala de aula, porém só se configuraram como Saberes Históricos se estas informações ou conhecimentos forem tratados sob o domínio de elementos específicos da disciplina de História.

Para tanto em nossa pesquisa trabalhamos com a conceituação que Charlot ( 1997) estabelece para estas categorias : informação, conhecimento e saber.Segundo o autor não há "saber" sem relação com o saber, não podemos simplesmente acessar o "saber" em um livro, internet ou qualquer banco de dados, porém a informação possui esta característica, se encontra fora do sujeito pode ser estocada, armazenada e acessada por qualquer individuo, é por natureza transmissível. Já o conhecimento é o resultado de experiências pessoais e está ligado ao campo da subjetividade, é provido de qualidades afetivo-cognitivas sendo intransmissível.

O saber é a relação entre - a apropriação de informações, o conhecimento pessoal e outros saberes é algo transmissivel, um produto comunicável e organizado por quadros metodológicos fruto de relações interpessoais e intrapessoais, ou seja, o saber é produzido pelo sujeito, porém este saber é confrontado com outros sujeitos que co-constroem, validam e partilham este saber.

Qual a importância destes Saberes em uma aula de História? Entendemos que o ensino de Historia não se reduz a simples transmissão de Conhecimentos ou Conteúdos Históricos sejam estes disponibilizados em livros didáticos ou aulas expositivas. Este ensino deveria estar fundamentado na construção do conhecimento histórico, o aluno deveria estabelecer relações entre o passado estudado e sua realidade, entender que este conhecimento é resultado de pesquisas historiográficas sendo estas construções humanas. Para isso o professor deveria dominar o conjunto teórico metodológico específico da disciplina História, ter a clareza das estratégias cognitivas de produção deste conhecimento.

Os questionários visam ampliar nossa análise sobre os saberes históricos 
dos professores. Como afirmamos, a realidade da sala de aula pode e influência na atividade docente, assim através dos questionários expandimos a possibilidade do professor demonstrar seus saberes, mesmo que não os desenvolva na prática. Para a formulação dos questionários finais que seriam aplicados aos sujeitos da pesquisa, levamos em consideração primeiramente, a melhor forma de obtermos informações a respeito destes saberes. Por se tratar de um estudo qualitativo de investigação o instrumento de pesquisa deveria ser submetido primeiramente a um teste para analisarmos a validade e profundidade das questões contidas no instrumento. Foi necessário averiguarmos se a forma como as questões estavam constituídas revelaria ou não os elementos que estávamos a investigar. Para isto desenvolvemos, previamente, um estudo exploratório com professores das séries iniciais, para então a partir do piloto utilizado, aperfeiçoar o questionário final.

0 objetivo do estudo exploratório é verificar previamente um modelo do perfil dos professores das séries iniciais e desta forma apontar diretrizes e parâmetros na formulação dos instrumentos de pesquisa durante o período de observação e posteriormente, na confecção e aplicação dos questionários. A aplicação de um questionário piloto, antecedendo a aplicação do questionário final, se baseia na abordagem metodológica bem como na modalidade de pesquisa utilizada neste trabalho. Devido ao caráter qualitativo de investigação compreendemos a necessidade de um contato prévio com o tema e o objeto de pesquisa, desta forma poderíamos rever e compreender mais claramente a realidade escolar, adequando nosso instrumento de pesquisa.

0 questionário piloto foi dividido em duas partes, a primeira com oito questões de assinalar abordando informações técnicas sobre formação profissional e a segunda sobre a prática docente e sua relação com 0 ensino de História. Foram aplicados quatro questionários em uma escola particular radicada na cidade de Londrina, esta escola se denomina de Piagetiana ${ }^{5}$. A escolha da escola se deu devido a contatos anteriores, pois já desenvolvemos trabalhos na escola que possui a característica de apoiar pesquisas educacionais. A primeira parte do questionário consistiu em analisar dados pessoais e

5 Várias escolas ao trabalharem com as séries iniciais se denominam Piagetianas no sentido que trabalham com o cotidiano dos alunos e não utilizam livros didáticos. Neste trabalho não abordaremos as características da escola e também não levamos em consideração esta denominação. 
a formação profissional. Todas as quatro pesquisadas eram mulheres. Quanto à formação três são formadas em Pedagogia e a outra ainda estava na graduação, também em pedagogia. Duas formadas em pedagogia concluíram seus cursos em instituições públicas de ensino superior, no caso, a Universidade Estadual de Londrina, ambas tem mais de dez anos de atuação profissional. Das outras duas professoras uma é formada pela Universidade Norte do Paraná, sendo esta a única especialista e a outra ainda está cursando Pedagogia no Centro Universitário Filadélfia, apesar de lecionar há dezesseis anos pois tem magistério. Ambas as instituições são privadas.

A segunda parte do questionário contou com onze questões sobre a prática docente das professoras em sala de aula. Das onze questões sugeridas nos questionários iremos, neste artigo, analisar apenas as três que visavam extrair informações sobre o ponto central da pesquisa, a relação dos professores com os saberes históricos.

Uma das questões que levantamos por achar essencial para o nosso trabalho consistiu em investigar se as entrevistadas em questão tiveram a disciplina Metodologia do Ensino de História $a^{6}$ nos cursos de pedagogia. 0 objetivo desta questão foi verificar se durante a formação em Pedagogia, professores que darão aula de História, tiveram contato com conhecimentos específicos da disciplina. Das quatro professoras pesquisadas três responderam não terem tido esta disciplina durante sua formação e uma fez confusão com a disciplina de História da Educação.

0 fato das professoras entrevistadas não terem tido a disciplina de metodologia é um fator que pode revelar uma despreocupação dos cursos de formação de pedagogia com as disciplinas específicas e com os conhecimentos da ciência de referência destas. Não podemos afirmar categoricamente que isto se repete em todos os cursos de Pedagogia espalhados pelo país, mas com certeza podemos afirmar que os programas dos cursos de pedagogia ${ }^{7}$ da cidade de Londrina não apresentam ou na apresentavam esta disciplina, pois em

\footnotetext{
6 Trabalhamos no questionário apenas com a disciplina de metodologia de ensino de história pois em pesquisa realizada por nós nos cursos de pedagogia não foi encontrada em nenhum curso disciplinas específicas das matérias a serem ensinadas nas séries iniciais; matemática, português, ciências, história, geografia, nos currículos consta apenas as disciplinas de metodologia de ensino.

7 Temos que lembrar aqui o período de formação das professoras na Universidade Estadual de Londrina que hoje já conta com disciplinas de metodologias especificas em cada área. No caso nas universidades particulares a disciplina é concentrada em Metodologia das séries iniciais.
} 
nosso universo investigado temos representantes das três maiores universidades do município.

A pergunta seguinte teve como objetivo mapear o conhecimento sobre a função do ensino de história e qual a utilidade da disciplina. As respostas seguem uma linha no sentido de levar o aluno a conhecer o passado para entender o presente, três professoras afirmam que uma das funções do ensino de História seria, através do estudo do passado, questionar, mudar, estabelecer relações ou mesmo criar hipóteses sobre o futuro. Vejamos a fala da professora quando perguntamos sobre qual a função do ensino de história "Fornecer aos alunos condições de reversibilidade ao pensamento e a noção de tempo, compreender processos e transformações (fenômenos), entender o passado como o conjunto do que veio antes de tudo que existe agora e criar hipóteses sobre como será o futuro" (Professora A)

Em nosso entendimento é interessante observar que mesmo sem formação inicial especifica em história ou mesmo sem terem tido em contato com conteúdos da disciplina no curso de graduação em Pedagogia a função de orientação temporal aparece em todas as falas, porém no estudo do passado ainda prevalece à idéia de previsão do futuro. Esta visão de uma história que poderia prever o futuro fez parte das discussões sobre o conhecimento histórico até metade do século XX quando novos estudos historiográficos começaram a confrontar esta idéia. 0 estudo sistemático do passado, a História, não possui a qualidade ou pretensão de prever o futuro e sim de apontar possibilidades de ação, orientando o sujeito no processo temporal. (Rusen,2001)

Entre as perguntas que constam do questionário, a análise dos problemas que as professoras enfrentam para ensinar história pode nos ajudar a entender como a ausência de discussões na formação inicial sobre o ensino de história contribui para as dificuldades que o ensino da disciplina nas séries iniciais do ensino fundamental. Na pergunta que indagava sobre as dificuldades com 0 ensino de História verificamos que três professoras apontam à deficiência das fontes e dos materiais pedagógicos e uma cita a falta de conhecimento específico.

Duas professoras afirmam não encontrarem fontes, materiais com diferentes pontos de vistas, dificultando assim o trabalho em sala, a outra diz que os materiais são defasados e não apresentam recursos para explorar a História. A docente afirma que sua dificuldade no ensino de história estaria em 
"Encontrar fontes de pesquisas que defendam diferentes visões dos acontecimentos". (Professora B) A outra professora salienta que "Não houve nenhuma mudança nos materiais pedagógicos. A história continua antiga sem muitos recursos para explorar" (Professora D) Apenas uma das professoras pesquisadas aponta a falta do conhecimento sistemático como dificuldade em ensinar História.

Percebemos nas respostas destas três professoras que as dificuldades do ensino de história estariam alocadas nos matérias pedagógicos. Duas colocações em pólos opostos nos chamou bastante a atenção, a primeira é que apenas uma professora afirma que a falta de conhecimento sistemático, especifico da disciplina História, é um problema no ensino de História. Isto demonstraria em uma primeira análise que para alguns professores formados em pedagogia 0 saber especifico das disciplinas não seriam necessários, apenas o "saber ensinar", aliado a um bom material pedagógico garantem uma boa aula de História. A segunda questão diz respeito a uma das categorias essenciais na construção e ensino da história que é a problemática das fontes e suas confrontações. Uma professora argumenta sobre uma das constatações levantadas por pesquisadores com relação ao ensino de história nas séries iniciais que é a questão da visão única da história como verdade absoluta. No entanto a professora afirma que o maior problema que enfrenta é a dificuldade de fontes que possam ser confrontadas, ou seja, mesmo sem os conhecimentos específicos da área esta professora tem 0 conhecimento da necessidade de confrontação de fontes e em última instância a percepção de que a História não é uma verdade inquestionável.

0 estudo exploratório realizado previamente contribuiu para a pesquisa em duas frentes, primeiro na formulação das perguntas do questionário final e segundo na própria metodologia de pesquisa em campo. Quanto à estruturação do questionário final, o questionário piloto nos sugeriu algumas modificações quanto às formulações das perguntas, pois percebemos que duas questões que foram utilizadas no piloto provocaram alguma confusão. A primeira questionava: Qual a função do ensino de história? E a segunda: Qual a importância de se estudar História para os alunos? Três professoras responderam na segunda que já haviam respondido na questão de anterior. Desta forma formulamos a parir das duas uma única questão: Qual a função 
do ensino de História na formação dos alunos. Assim sendo a professora poderia articular as suas respostas, já que este era o objetivo inicial..

Outra modificação no questionário foi a adição de outra questão que tratasse sobre a formação dos conceitos históricos, visto sua importância na formação histórica dos alunos, descritos anteriormente pela linha de pesquisa Educação histórica.

Quanto à metodologia, percebemos que a observação deveria anteceder a aplicação dos questionários. Acreditamos que 0 teor das perguntas contidas nos questionários poderia influenciar no andamento das aulas, direcionandoas no mesmo sentido, contaminando por sua vez os resultados das observações.

Através do estudo exploratório, notamos que as professoras pesquisadas não tiveram em sua formação a disciplina de metodologia de ensino de história, sendo um dos motivos o fato de serem formadas a algum tempo, desta forma escolhemos professoras formadas recentemente, isso é claro, na medida do possivel.

Encontramos entre as respostas do estudo exploratório, alguns elementos que demonstram certa fragilidade conceitual,saberes históricos confusos, uma certa dificuldade de entender para que serve a formação histórica nos alunos, o que nos apontou, ainda que de maneira restrita, alguns elementos prévios sobre o encaminhamento da pesquisa final.

0 que se pode ver nas respostas do questionário piloto é que os professores atribuem grande importância aos livros didáticos sendo estes a fonte do saber sistemático, especifico da História, restando aos professores apenas mediar este conhecimento. Notamos também que apesar da formação inicial não contribuir para a construção de conceitos e saberes na área de história, a experiência, os materiais didáticos e com certeza cursos de formação continuada acabaram por preencher algumas das lacunas desta formação. Apesar de apenas uma professora reconhecer a falta destes saberes em sua formação acreditamos que este fato se dá por acharem que este conteúdo pode ser ensinado pelo livro didático. Segundo Nunes, em sua pesquisa sobre o ensino de história nas séries iniciais, "A maioria das professoras que trabalhava com as séries iniciais do ensino fundamental seguia, na prática de sala de aula, a proposta programática de algum livro didático. (NUNES, 2004, p.82) nesse sentido a autora argumenta que 0 uso do livro didático como fonte exclusiva em sala de aula, pode 
comprometer a formação dos alunos;

A utilização dos livros didáticos pelas professoras das séries iniciais faz com que o ensino de História seja trespassado pelos mesmos problemas apresentados pelo livro. Desta maneira, torna-se um ensino de concepção tradicional, conservadora e positivista e que se apresenta de forma narrativa, factual, acrítica e cronológica. Não raro veicula preconceitos e estereótipos. (NUNES, 2004, p.83)

Podemos notar nas respostas sobre a temporalidade histórica, alguns elementos próximos as competências descritas por Rusen (2007b). Apesar da caracterização, deslocada, da História como elementos de previsão do futuro, percebemos em suas respostas as preocupações do ensino de história em estudar as relações entre passado e presente, para a orientação da vida prática dos alunos. Partindo da premissa de que estes professores não tiveram em sua formação a disciplina específica de ensino de História, uma questão instigante se colocou para a pesquisa como e de que forma estas professoras elaboraram suas respostas? Qual a origem dos saberes históricos apresentados?

\section{Referências}

CAINELLI, Marlene. Educação Histórica: Perspectivas de aprendizagem da história no ensino fundamental In: EDUCAR EM REVISTA. Curitiba. In. especial. P.57-72, Ed. UFPR 2006.

CHARLOT, Bernard. Da relação com o saber: Elementos para uma teoria. Porto Alegre: Artes Médicas Sul, 2000.

LEE, Peter (2003). "Nós fabricamos carros e eles tinham que andar a pé. Compreensão da vida no passado. "We're making cars, and they just had to walk": understanding people in the past (19-36). In BARCA, Isabel (org). Educação Histórica e museus. Actas das 2as. jornadas internacionais de educação histórica. Braga: Universidade do Minho.

NUNES, Silma do Carmo. 0 ensino de história nas séries iniciais do ensino fundamental. Caderno de História, Uberlândia, v.12/13 p.79-102, set92/ago.93.

OLIVEIRA, Sandra Regina Ferreira de. 0 ensino de história nas séries iniciais: Cruzando as fronteiras entre a História e a Pedagogia. História \& Ensino, Londrina v. 9 p. 259272, out. 2003. 
RÜSEN, Jorn. Didática da História: Passado, presente e perspectivas a partir do caso alemão. Práxis Educativa. Ponta Grossa, PR. V. 1, n. 2, jul.-dez. 2006.

Razão Histórica. Teoria da História: Os fundamentos da ciência histórica. Brasília Ed. Universidade de Brasília, 2001>

Reconstrução do Passado. Teoria da História II: os princípios da pesquisa histórica. Brasília Ed. Universidade de Brasília, 2007.

SHIMIDT, Maria Auxiliadora. Construindo conceitos no ensino de história: "A captura lógica" da realidade social. História e Ensino. Londrina v.5, p. 147-163, out. 1999.

\section{The Historical Knowledge of elementary Series Teachers: some perspectives of teaching in classroom}

ABSTRACT

This article intends to show and discuss the first results of my master dissertation in education done at Estate University of Londrina. The current research has the objective of investigating if teachers who teach primary school have the theoretical and methodological foundations of historical subjects and how this is shown in practice.

The research will be based on the analysis of elementary teachers of the Municipal School situated in Cambé city. The model of the research will be qualitative of investigation, emphasizing more the process than the product.

This study is in the stage of crossing information and conclusion.

Key-words: Teaching of History, Historical Knowledge, Elementary series 